\title{
COMPARISON OF OVULATION INDUCTION LETROZOLE AND CLOMIPHENE CITRATE IN SUBFERTILE WOMEN WITH POLYCYSTIC OVARIAN SYNDROME
}

\author{
Amna Shafiq, Rabiya Akbar, Uzma Urooj*, Sadaf Zohra, Shazia Afzal, Madiha Tanveer \\ Combined Military Hospital/National University of Medical Sciences (NUMS) Rawalpindi Pakistan, *Pak Emirates Military Hospital/National University of \\ Medical Sciences (NUMS) Rawalpindi Pakistan
}

\begin{abstract}
Objective: To compare the ovulation induction of letrozole and clomiphene citrate in sub-fertile women with polycystic ovarian syndrome.

Study Design: Quasi experimental study.

Place and Duration of Study: Combined Military Hospital Rawalpindi, from Jun 2018 to Aug 2019.

Methodology: A total of 116 married sub-fertile women with polycystic ovarian syndrome, 16-40 years of age were included. Patients with previous surgery related to genital tract, hypothyroidism and chronic renal failure were excluded. Letrozole 5.0 mg daily from Day 5-9 of menstruation was prescribed to group A women and clomiphene citrate 100 mg daily from Day 5-9 of menses was given to group B women.

Results: In group A and in group B, mean age was $29.78 \pm 4.71$ years and $29.95 \pm 4.22$ years respectively. Most of the patients $59(50.86 \%)$ were between 18-30 years of age. Mean duration since marriage was $4.23 \pm 1.42$ years. Mean body mass index was $29.71 \pm 2.65 \mathrm{~kg} / \mathrm{m}^{2}$. Frequency of ovulation of clomiphene citrate and letrozole in sub-fertile women with polycystic ovaries was $28(42.28 \%)$ versus $42(72.41 \%)$ respectively ( $p$-value $=0.008)$.

Conclusion: This study concluded that ovulation induction of letrozole is better than clomiphene citrate in sub-fertile women with polycystic ovarian syndrome.
\end{abstract}

Keywords: Clomiphene citrate, Letrozole, Polycystic ovarian syndrome, Subfertility.

How to Cite This Article: Shafiq A, Akbar R, Urooj U, Zohra S, Afzal S, Tanveer M. Comparison of Ovulation Induction Letrozole and Clomiphene Citrate in Subfertile Women with Polycystic Ovarian Syndrome. Pak Armed Forces Med J 2021; 71(5): 1844-1847. doi:https://doi.org/10.51253/pafmj.v71i5.6554

This is an Open Access article distributed under the terms of the Creative Commons Attribution License (https://creativecommons.org/licenses/by-nc/4.0/), which permits unrestricted use, distribution, and reproduction in any medium, provided the original work is properly cited.

\section{INTRODUCTION}

In the women of reproductive age group out of all the endocrinopathies polycystic ovarian syndrome (PCOS) is one of the most common, affecting up to 5$10 \%$ of women. ${ }^{1}$ These women suffer from anovulatory sub-fertility. It has been found that lifestyle modification with weight reduction in obese women with PCOS, clomiphene citrate (CC) is the first line treatment for ovulation induction (OI). ${ }^{2}$ Approximately, 75$80 \%$ of women have ovulation after ovulation induction with clomiphene citrate. However, there is a discrepancy between the ovulation rate and pregnancy rate, which was reported to be $22 \%$ per each ovulating cycle after CC. ${ }^{3}$ Oher treatments are, gonadotrophin injections as well as laparoscopic ovarian drilling. These treatments have disadvantages, which are, costly treatments, risks of ovarian hyperstimulation syndrome and multiple pregnancy. ${ }^{4}$

One of a potentially better substitutes to $\mathrm{CC}$ is a specific aromatase inhibitor, letrozole which acts by reducing estrogen synthesis. ${ }^{5}$ Due to this function

Correspondence: Dr Uzma Urooj, Gynae/Obs Department, Pak Emirates Military Hospital, Rawalpindi Pakistan

Received: 10 Apr 2021; revision received: 23 Aug 2021; accepted: 01 Sep 2021 letrozole does not causes any anti-estrogenic effects on endometrium which is supported by recent studies reporting adequate endometrial thickness while having letrozole treatment. Furthermore, letrozole is rapidly eliminated from body due to its $45 \mathrm{hr}$, short half-life as compared to CC which have 2 weeks long half-life, leading to late follicular rise in circulating estrogen thereby enhancing endometrial development with subsequent increase in the chances of pregnancy. The rising estrogen levels may also result in a shorter Folliclestimulating hormone (FSH) window (mimicking the physiological cycle) with subsequent monoovulation and a lower risk of multiple pregnancy.6,7 Due to ovulation rates of approximately $85 \%$ and pregnancy rates of $35-40 \%$, CC was used as standard first-line ovulation induction (OI) agent for women with polycystic ovarian syndrome (PCOS) for several decades. ${ }^{8}$ Few studies reported the frequency of ovulation by clomiphene citrate and letrozole in sub-fertile women with polycystic ovarian syndrome as $70.21 \%$ vs $41.25 \%$ respectively. ${ }^{9}$ In another study, the efficacy (in terms of ovulation) of clomiphene citrate and letrozole in infertile women with polycystic ovarian syndrome was $82.90 \%$ vs $62.5 \%$ respectively. ${ }^{10}$ 
As the letrozole is newly introduced drug in general practice for ovulation in sub-fertile women with polycystic ovarian syndrome, so its efficacy in terms of ovulation should be strongly assessed before using it as a routine drug in our general practice. Although previously immense body of literature is present on this topic but as described above some studies have shown clomiphene citrate better while other showed letrozole better, so on the basis of these studies, we cannot make a conclusion of better drug among this. The rationale of study was to compare the efficacy (in terms of ovulation) of letrozole and clomiphene citrate in sub-fertile women with polycystic ovarian syndrome. As routinely clomiphene citrate is used in majority of our setups, so this study will provide the evidence of letrozole use in PCOS. If this drug will be proved more useful, then this study will encourage our clinicians for its routine use for treating subfertility in polycystic ovarian syndrome patients which ultimately increase the pregnancy rates in these particular patients and thus improve the psychosocial life of these particular patients.

\section{METHODOLOGY}

It was a cross sectional comparative study carried out at department of Gynecology and Obstetrics, Combined Military Hospital, Rawalpindi from June 2018 to August 2019. The sample size was 116 i.e. 58 in both groups with $95 \%$ confidence level, $80 \%$ power of study, taking expected efficacy (in terms of ovulation) of clomiphene and letrozole in sub-fertile women with polycystic ovarian syndrome as $82.90 \%$ and $62.50 \%$ respectively. ${ }^{10}$ By using World Health Organization (WHO) sample size calculator for two proportions, ${ }^{10}$ sample size calculated. Convenience sampling was used to recruit the study participants.

Inclusion Criteria: About 16-40 years old married subfertile women with polycystic ovarian syndrome were included.

Exclusion Criteria: Women with prolactin levels $>500$ $\mathrm{mIU} / \mathrm{L}$, history of previous surgery related to genital tract, patients with chronic renal failure (assessed on history and s/creatinine $>1.5 \mathrm{mg} / \mathrm{dl}$ ) and hypothyroidism $(\mathrm{TSH}>5.2 \mathrm{mIU} / \mathrm{L}, \mathrm{T} 3<70 \mathrm{ng} / \mathrm{dl}$ and $\mathrm{T} 4<5.2$ $\mu \mathrm{g} / \mathrm{dl})$ were excluded.

Total 116 women fulfilling the inclusion criteria presented in OPD were selected Approval from institutional ethical review committee (IR/313/19) was taken. After taking informed consent from each patient, participants were divided into two groups by using lottery method. Women selected slips from total mixed up slips (half-slips contained letter ' $A$ ' and other half-slips contained letter ' $\mathrm{B}$ ') and was placed in that respective group. Letrozole 5.0 mg daily from Day 5-9 of menstruation was prescribed to group A women and clomiphene $100 \mathrm{mg}$ daily from day 5 of menses till 9th day, was given to group B women. In both groups' treatment was given for 12 weeks at which efficacy was noted by the researcher.

All the data were entered and analyzed by using Statistical Package for the Social Sciences (SPSS) version 23. Age, duration of marriage and BMI were presented as mean and standard deviation. Categorical variables were presented as frequency and percentages. Association between both groups was compared by Chi-square test and $p$-value $\leq 0.05$ was considered as statistically significant.

\section{RESULTS}

A total of 116 patients included in study. Age range in this study was from 16 to 40 years with mean age of $29.82 \pm 4.64$ years. The mean age of women in group A was $29.78 \pm 4.71$ years and in group B was $29.95 \pm 4.22$ years. Majority of the patients 59 (50.86\%) were between 18-30 years of age. Mean duration since marriage was $4.23 \pm 1.42$ years, mean BMI was $29.71 \pm$ $2.65 \mathrm{~kg} / \mathrm{m}^{2}$.

In our study, frequency of ovulation of clomiphene citrate and letrozole in infertile women with polycystic ovarian syndrome was $28(48.28 \%)$ versus $42(72.41 \%)$ respectively $(p$-value $=0.008)$ shown in the Table-I.

Ovulation according to BMI $\leq 27$ in group A was $10(17.2 \%)$ and in group B was $07(12 \%)$ and ovulation BMI $>27$ in group A was $32(55.1 \%)$ and in group B was $21(36.2 \%)$ there was no significant association $p>0.05$ in both group shown in Table-II.

Table-I: Comparison of patients according to ovulation induction.

\begin{tabular}{l|c|c|c}
\hline Ovulation & $\begin{array}{c}\text { Group A (n=58) } \\
\text { Letrozole }\end{array}$ & $\begin{array}{c}\text { Group B (n=58) } \\
\text { Clomiphene }\end{array}$ & p-value \\
\cline { 1 - 3 } Yes & $42(72.41 \%)$ & $28(48.28 \%)$ & \multirow{2}{*}{0.008} \\
\cline { 1 - 3 } No & $16(27.59 \%)$ & $30(51.72 \%)$ & \\
\cline { 1 - 3 }
\end{tabular}

Table-II: Ovulation with respect to the body mass index.

\begin{tabular}{l|c|c|c|c|c}
\hline $\begin{array}{l}\text { BMI } \\
\left(\mathbf{k g} / \mathbf{m}^{2}\right)\end{array}$ & \multicolumn{2}{|c|}{$\begin{array}{c}\text { Group A (n=58) } \\
\text { Ovulation }\end{array}$} & \multicolumn{2}{c|}{$\begin{array}{c}\text { Group B (n=58) } \\
\text { Ovulation }\end{array}$} & $\begin{array}{c}p- \\
\text { value }\end{array}$ \\
\hline & Yes & No & Yes & No & \\
\hline$\leq 27$ & $\begin{array}{c}10 \\
(17.2 \%)\end{array}$ & $\begin{array}{c}04 \\
(6.8 \%)\end{array}$ & $\begin{array}{c}07 \\
(12 \%)\end{array}$ & $\begin{array}{c}07 \\
(12 \%)\end{array}$ & 0.246 \\
\hline$>27$ & $\begin{array}{c}32 \\
(55.1 \%)\end{array}$ & $\begin{array}{c}12 \\
(20.6 \% 0\end{array}$ & $\begin{array}{c}21 \\
(36.2 \%)\end{array}$ & $\begin{array}{c}23 \\
(39.6 \%)\end{array}$ & 0.017 \\
\hline
\end{tabular}

There was no statistically significance difference between ovulation with marriage duration $\leq 5 \quad(p=0.109)$ 
while there was statistically significance difference between ovulation with marriage duration $>5 \quad(p=0.010)$ shown in Table-III.

Table-III: Ovulation with respect to the duration of marriage.

\begin{tabular}{l|c|c|c|c|c}
\hline $\begin{array}{l}\text { Duration of } \\
\text { Marriage }\end{array}$ & \multicolumn{2}{|c|}{$\begin{array}{c}\text { Group A (n=58) } \\
\text { Ovulation }\end{array}$} & \multicolumn{2}{c|}{$\begin{array}{c}\text { Group B (n=58) } \\
\text { Ovulation }\end{array}$} & $\begin{array}{c}p \text { - } \\
\text { value }\end{array}$ \\
\hline & Yes & No & Yes & No & \\
\hline$\leq 5$ & $\begin{array}{c}31 \\
(53.4 \%)\end{array}$ & $\begin{array}{c}14 \\
(24.1 \%)\end{array}$ & $\begin{array}{c}23 \\
(39.6 \%)\end{array}$ & $\begin{array}{c}21 \\
(36.2 \%)\end{array}$ & 0.109 \\
\hline$>5$ & $\begin{array}{c}11 \\
(18.9 \%)\end{array}$ & $\begin{array}{c}02 \\
(3.4 \%)\end{array}$ & $\begin{array}{c}05 \\
(8.6 \%)\end{array}$ & $\begin{array}{c}09 \\
(15.5 \%)\end{array}$ & 0.010 \\
\hline
\end{tabular}

\section{DISCUSSION}

One of the most common causes of anovulatory sub-fertility is Polycystic ovarian syndrome (PCOS) causing $70 \%$ of infertility cases due to anovulation. ${ }^{11}$ One of the most common drugs used since 1960 is clomiphene citrate (CC) with an ovulation rate of $60-85 \%$ but a conception rate of only about $20 \% .{ }^{12}$ Due to long half-life (2 weeks) of clomiphene citrate may have a negative effect on the cervical mucus and endometrium, leading to discrepancy between ovulation and conception rates. ${ }^{13,14}$ This leads to the search for a compound capable of inducing ovulation by avoiding the adverse antiestrogen effects of CC. it has been found in recent studies that Letrozole, which is an aromatase inhibitor, does not possess the adverse anti-estrogenic effects of clomiphene and is associated with higher pregnancy rates than CC treatment in patients with PCOS. ${ }^{15}$ But evidences from larger trials are still awaited, some encouragement may be taken from the success of preliminary results showing aromatase inhibitor Letrozole may be regarded as a possible replacement for CC for the first-time treatment of anovulatory subfertility. ${ }^{16}$

This study is very much comparable to studies of Fouda UM et a and Sherif et al, which showed, mean age of 28 years and 29 years respectively. ${ }^{17}$ On the other hand, Hussain et al, in his study has shown a larger mean age i.e. 32 years, compared to our study. ${ }^{18}$ Mean duration since marriage was $4.23 \pm 1.42$ years. This is very much comparable to the study of Hussain NHN et al, ${ }^{19}$ who had observed this as 4.5 years, but a little higher than Fouda et al, ${ }^{20}$ who had found this as 3.6 years. This late presentation in our society may be due to hakeem culture, lack of awareness, some social constraints and economic hurdles.

Hendawy et al, showed that Letrozole had a better effect on endometrial thickness and pregnancy rate than Clomiphene citrate. ${ }^{21}$ Roy et al, compared the efficacy of Letrozole and Clomiphene citrate in PCOS patients with infertility; they concluded that Letrozole had a better endometrial response and pregnancy rate compared with Clomiphene citrate. ${ }^{22}$ In a study by $\mathrm{Xi}$ et al, use of Letrozole and Clomiphene citrate combined with gonadotropins in Clomiphene-resistant infertile women with PCOS was evaluated the rate of unifollicular development was $80.2 \%$ in the Letrozole + high mobility group (HMG), 65.3\% in the Clomiphene citrate + HMG group, and $54.7 \%$ in the HMG-only group. The difference between these three groups was significant statistically. Endometrial thickness in the group receiving Letrozole was higher than other two groups. ${ }^{23}$

Requena et al, ${ }^{24}$ in their literature review looked at randomized trials comparing letrozole versus clomiphene as first line therapy and included four studies. The ovulation rate for letrozole in comparison with clomiphene did not differ significantly (OR 1.7; 95\% CI $0.66-2.09)$ nor did the pregnancy rate per patient (OR $1.37 ; 95 \%$ CI 0.70-2.71).

Letrozole has now been in use as an ovulation induction agent for more than a decade. Even though emerging evidence suggests that it is an effective ovulation induction agent, comparable if not better than clomiphene. In a local randomized controlled trial, ${ }^{25}$ a total of 212 patients of age 20-38 years with anovulatory infertility were included. These patients were placed randomly into group A (clomiphene citrate) and group B (letrozole). The mean age of women in group A was $26.67 \pm 4.23$ and in group B was $26.24 \pm 4.18$ years. The mean duration since marriage in group A was $4.06 \pm 1.95$ years and in group B $4.26 \pm 2.12$ years. Efficacy of clomiphene citrate was $10.38 \%$ while that of letrozole was $21.70 \%(p=0.02) .{ }^{25}$

When clomiphene citrate is used as first line therapy in anovulatory women, one can expect a $25 \%$ incidence of clomiphene resistance. It has been established that although ovulation rates are in the range of $75 \%$ only $30-40 \%$ will actually conceive. Hence, about $60-$ $65 \%$ of anovulatory women being treated with clomiphene will fall into either the resistant or failure group. Letrozole has been shown to be effective in women with either clomiphene resistance or failure. Letrozole has now been in use as an ovulation induction agent for more than a decade. Even though emerging evidence suggests that it is an effective ovulation induction agent, comparable if not better than clomiphene. Therefore, on the whole it is concluded that orally administered letrozole is more efficacious than clomi- 
phene citrate in women with polycystic ovarian syndrome.

\section{CONCLUSION}

This study concluded that ovulation induction of letrozole is better than clomiphene citrate in sub-fertile women with polycystic ovarian syndrome. Therefore, we recommend that letrozole should be used as a first line therapy in sub-fertile women with polycystic ovarian syndrome which ultimately increases the ovulation induction and pregnancy rates in these particular patients.

\section{Conflict of Interest: None.}

\section{Authors' Contribution}

RK: Data collection, UU: Conceptual framework, literature review, SZ: Data collection, SA: Data collection, MT: Conceptual framework.

\section{REFERENCES}

1. Orio F, Palomba S. Reproductive endocrinology: new guidelines for the diagnosis and treatment of PCOS. Nat Rev Endocrinol 2014; 10(2): 130-132.

2. Hecht Baldauff N, Arslanian S. Optimal management of polycystic ovary syndrome in adolescence. Arch Dis Child 2015; 100(11): 1076-1083.

3. Susan MS, Kristen AP. Epidemiology diagnosis and management of polycystic ovary syndrome. Clin Epidemiol 2014; 6(7): 1-13.

4. Palomba S. Aromatase Inhibitors for Ovulation Induction. J Clin Endocrinol Metab 2015; 100(5): 1742-1747.

5. Klement $\mathrm{AH}$, Casper RF. The use of aromatase inhibitors for ovulation induction. Curr Opin Obstet Gynecol 2015; 27(2): 206209.

6. Amer SA, Smith J, Mahran A, Fox P, Fakis A. Double-blind randomized controlled trial of letrozole versus clomiphene citrate in sub-fertile women with polycystic ovarian syndrome. Human Reprod 2017; 32(1): 1631-1638.

7. Legro RS, Brzyski RG, Diamond MP, Coutifaris C, Schlaff WD, Casson $\mathrm{P}$, et al. Letrozole versus clomiphene for infertility in the polycystic ovary syndrome. N Engl J Med 2014; 10(2): 119-129.

8. Amer SA, Smith J, Mahran A, Fox P, Fakis A. Double-blind randomized controlled trial of letrozole versus clomiphene citrate in sub-fertile women with polycystic ovarian syndrome. Obstet Gynecol Sur 2017; 72(11): 657-658.

9. Al-Shaikh SF, Al-Mukhatar EJ, Al-Zubaidy AA, Al-Rubaie BJU, Al-Khuzaee L. Use of clomiphene or letrozole for treating women with polycystic ovary syndrome related subfertility in Hilla city. Middle East Fertil Soc J 2017; 22(2): 105-110.

10. Sharief M, Nafee NR. Comparison of letrazole and clomiphene citrate in women with polycystic ovaries undergoing ovarian stimulation. J Pak Med Assoc 2015; 65(4): 1149-1152.

11. Hendawy SF, Samaha HE, Elkholy MF. Letrozole versus clomiphene citrate for induction of ovulation in patients with polycystic ovarian syndrome undergoing intrauterine insemination. Clin Med Insights Reprod Health 2011; 5(2): 11-15.
12. Xi W, Liu S, Mao H, Yang Y, Xue X, Lu X. Use of letrozole and clomiphene citrate combined with gonadotropinsin clomipheneresistant infertile women with polycystic ovary syndrome: a prospective study. Drug Des Devel Ther 2015; 9(2): 6001-6008.

13. Fleming R, Hopkinson ZE, Wallace AM, Greer IA, Sattar N. Ovarian function and metabolic factors in women with oligomenorrhea treated with metformin in a randomized double-blind placebo-controlled trial. J Clin Endocrinol Metab 2002; 87(7): 569574.

14. Fisher SA, R Reid RL, Van Vugt DA, Casper RF. A Randomized double-blind comparison of the effects of clomiphene citrate and the aromatase inhibitor letrozole on ovulatory function in normal women. Fertil Steril 2002; 78(3): 280-285.

15. Al-Fozan H, Al-Khadouri M, Tan SL, Tulandi T. A randomized trial of letrozole versus clomiphene citrate in women undergoing superovulation. Fertil Steril 2004; 82(2): 1561-1563.

16. Randall JM, Templeton A. Cervical mucus score and in vitro sperm mucus interaction in spontaneous and clomiphene citrate cycles. Fertil Steril 1991; 56(3): 465-468.

17. Atay V, Cam C, Muhcu M, Cam M, Karateke A. Comparison of letrozole and clomiphene citrate in women with polycystic ovaries undergoing ovarian stimulation. J Int Med Res 2006; 34(1): 73-76.

18. Polyzos NP, Tsappi M, Mauri D, Atay V, Cortinovis I, Casazza G. Aromatase inhibitors for infertility in polycystic ovary syndrome. The beginning or the end of a new era?. Fertil Steril 2008; 89(4): 278-280.

19. Fouda UM, Sayed AM. Extended letrozole regimen versus clomiphene citrate for superovulation in patients with unexplained infertility undergoing intrauterine insemination: a randomized controlled trial. Reprod Biol Endocrinol 2011; 9(4): 84-90.

20. Hendawy SF, Samaha HE, Elkholy MF. Letrozole versus Clomiphene citrate for Induction of Ovulation in patients with polycystic Ovarian syndrome Undergoing Intrauterine Insemination. Clinical Med Insights Reproduct Health 2011; 5(2): 11-16.

21. Roy KK, Baruah J, Singla S, Sharma JB, Singh N, Jain SK, et al. A prospective randomized trial comparing the efficacy of Letrozole and Clomiphene citrate in induction of ovulation in polycystic ovarian syndrome. Hum Reprod 2012; 5(1): 20-26.

22. Xi W, Liu S, Mao H, Yang Y, Xue X, Lu X. Use of Letrozole and Clomiphene citrate combined with gonadotropinsin clomipheneresistant infertile women with polycystic ovary syndrome: a prospective study. J Des Drg 2015; 9(1): 6001-6007.

23. Badawg A, Aal IA, Abulalta M. Clomiphene Citrate or Letrozole for ovulation induction in women with polycystic ovarian syndrome: A prospective randomized trial. Fertil Steril 2009; 92(3): 849-852.

24. Requena A, Herroro J, Landeras J, Navarro E, Neyro JL, Salvador $\mathrm{C}$, et al. Reproductive endocrinology interest group of the spanish society of fertility: use of letrozole in assisted reproduction: systemic review and metanalysis. Hum Reprod Update 2008; 14(3): 571-582.

25. Razzaq S, Rasheed S, Pansota MS, Fatima N. Efficacy in term of orally administered letrozole versus clomiphene citrate in anovulatory infertility. Gomal J Med Sci 2015; 13(11): 15-18. 